\title{
Overcoming the dependent variable problem in studying food policy
}

\author{
Jeroen Candel ${ }^{1}$ (D) $\cdot$ Carsten Daugbjerg ${ }^{2,3}$
}

Received: 31 October 2018 / Accepted: 12 November 2019 / Published online: 26 November 2019

(C) The Author(s) 2019

\begin{abstract}
The development of a comparative food policy research agenda has been hampered by the dependent variable problem of how to delineate the policy field. Through a concise literature review, we show that the existing literature has conceptualised food policy as policy outputs, institutional orders, or discursive constructs. Focusing on the policy outputs, we define food policy as a set of policy outputs adopted to address one or more food system activities (production, processing and packaging, distribution and retailing, and consumption) with the explicit aim of affecting food system outcomes in a desired direction. The paper develops a heuristic encompassing four dimensions along which food policy outputs may differ: (i) policy scope, (ii) targeting of policy efforts, (iii) type of policy instruments applied and how these are calibrated, and (iv) integration of the various components of the policy complex. These four dimensions can be applied to characterise individual food policies and compare across countries and time. Comparing and tracking the development of food policy along these dimensions would allow for addressing follow-up questions about impacts and what explains policy change.
\end{abstract}

Keywords Food policy $\cdot$ Comparative research $\cdot$ Dependent variable problem $\cdot$ Public policy $\cdot$ Food system

\section{Introduction}

Food systems across the world have come to face increasing pressures and challenges in recent decades. While about 800

\section{Highlights}

- Comparative food policy research has been hampered by a dependent variable problem

- We suggest that this problem can be overcome by focusing on policy outputs

- We propose a heuristic that encompasses four dimensions along which outputs differ

- These dimensions include: scope, targeting, substantiality and integration

- This approach can be used to compare food policies across contexts and over time

Jeroen Candel

jeroen.candel@wur.nl

Carsten Daugbjerg

cda@ifro.ku.dk

1 Public Administration and Policy Group, Wageningen University, Hollandseweg 1, 6706KN, Wageningen, Netherlands

2 Department of Food and Resource Economics, University of Copenhagen, Rolighedsvej 25, DK-1958 Copenhagen, Denmark

3 Crawford School of Public Policy, The Australian National University, Lennox Crossing, Acton ACT 0200, Australia million people still suffer from calorie deficiencies, approximately 2 billion people are victim of micronutrient malnutrition, and a similar and rapidly rising amount of people are overweight or obese (IFPRI 2016). Meanwhile, food systems have been shown to be vulnerable to global environmental change (Ingram et al. 2012), while also being one of the major sources of anthropogenic greenhouse gas emissions (Vermeulen et al. 2012). Furthermore, farmers' incomes and livelihoods are unstable in many regions (Van der Ploeg 2008), food safety and zoonoses continue to be a concern (WHO 2015), and the food system has been linked to biodiversity losses (Godfray et al. 2010), migration patterns (Crush 2013), and violent conflict (Rosin et al. 2012), inter alia. It may therefore not come as a surprise that academics, policymakers and a wide range of other stakeholders have called for a transition towards more sustainable and/or equitable food systems (e.g., Holt-Giménez and Patel 2012; Marsden and Morley 2014; iPES Food 2015; Barling 2016).

Recognising that many food system drivers and challenges transcend the boundaries of traditional governmental jurisdictions, scholars have recommended a shift towards more holistic ways of governing food systems, e.g., by elaborating notions of 'joined-up' or 'integrated' food policy or 'food systems governance' (e.g., Barling et al. 2002; Ericksen et al. 2009; Lang et al. 2009; MacRae 2011; Termeer et al. 2018). Indeed, food policy scholarship has rapidly expanded in recent 
decades, as is indicated by the emergence of a range of schools, societies, and conferences.

In recent years, the consequent body of thought has gradually come to be picked up by various governments and international organisations, marking a shift from abstract debates to actual food policy initiatives (Candel and Pereira 2017; iPES Food 2017). For example, the British government adopted a long-term food strategy in 2010 (which was never really implemented) (Marsden 2010; Parsons 2018), while countries like Sweden, Finland, the Netherlands, and Canada have more recently adopted or initiated the development of integrated food strategies. At the EU level, various commentators and stakeholders have called for a transition of the Common Agricultural Policy towards a Common Food Policy (e.g., Marsden 2015; Fresco and Poppe 2016; de Schutter 2017). In the Global South, many governments have developed more specific food or nutrition security approaches (Candel 2018); often using the successful Brazilian 'Fome Zero' program as blueprint (Marcondes and De Bruyn 2015).

In order to further the development of food policy and, ultimately, assess effects on the ground, it would be an important step for the research community to develop methods and tools for systematically comparing and tracking these emerging food policy efforts (cf. Berrang-Ford et al. 2011). Comparisons across time and contexts could provide insights into the number of governments (across levels) that have adopted food policies, the concerns they prioritise, and the instruments that have been deployed to steer food systems, inter alia; e.g., addressing pressing questions such as how many Sub-Saharan African governments have adopted integrated food security strategies, and to what extent these proceed beyond productionist goals (cf. Candel 2018). Such comparisons would be a precondition for follow-up studies and assessments with explanatory ambitions in terms of identifying the conditions enabling the adoption of particular variants of food policy, as well as for the systematic evaluation of the impacts of policy interventions across contexts; e.g., addressing research questions like whether the much-lauded Brazilian policy instrument mix for tackling food insecurity also sorts effect in different contexts (cf. Marcondes and De Bruyn 2015).

However, the development of such a comparative research agenda is hampered by what we refer to as the dependent variable problem of food policy research. As governments face varying food system challenges and have different priorities and preferred policy styles, there are considerable differences in the form and scope existing food policies take (e.g., Calori and Magarini 2015; De Cunto et al. 2017; Candel 2019). As we will show in Section 2, existing food policy conceptualisations are not sufficiently developed to take stock of this diversity, resulting in lack of clarity about and indistinctness of the nature and boundaries of the phenomenon that is being studied or compared (i.e. food policy). Thus, the problem does not concern "the "dependent variable" in the technical or statistical sense, but rather ... the challenge of conceptualising and measuring ... policy within and across cases.' (Dupuis and Biesbroek 2013: 1477).

Somewhat paradoxically, the analytical challenge that has come to be referred to as the dependent variable problem in comparative policy analyses (Green-Pedersen 2004; Howlett and Cashore 2009; Dupuis and Biesbroek 2013), is also crucial to studies that approach food policy as the independent variable. Policy is the independent variable of the study, when the scholar is interested in evaluating policy impacts. Most of the policy research in economics and public health treats policy as the independent variable when evaluating or estimating it effects in relation to a certain objective. Examples of such studies include Lentz and Barrett's (2013) comparison of the economics and nutritional impacts of different kinds of food assistance policies, the WHO's (2016) meta-analysis of the health effects of tax-based food policy interventions. Such assessments would be much helped by greater conceptual precision about the nature and scope of food policy interventions, as well as by systematically mapping and tracking these interventions across contexts and over time.

The dependent variable problem is not unique to studies of food policy (Howlett and Cashore 2009; Dupuis and Biesbroek 2013), but the inherently 'integrated' or 'holistic' nature of food policy makes the problem even more pressing as virtually any policy effort can be argued to have an impact on the food system in some way and thus be considered part of 'food policy'. The extent to which and how governments directly or indirectly integrate policies affecting the food system into a more or less coherent food policy (or food policy complex) varies significantly across countries. We therefore need to define what we are studying, comparing and debating. Are we, for example, focusing on policy outputs, institutional orders, or discursive constructs? In this paper, we propose to focus future comparative analyses on the measures that governments explicitly adopt to pursue food policy objectives. To map and compare food policies, we need a heuristic that can define the core dimensions of food policy and can be used to establish how these can vary across jurisdictions. Without an analytical device enabling policy analysts to identify and describe similarities and differences it is difficult, if not impossible, to map and compare systematically across jurisdictions; severely hampering opportunities for lesson drawing.

In this paper we address this challenge, aiming at providing a clear and precise conceptualisation of food policy that can serve as a point of departure for comparative studies. We start by taking a step back, presenting the outcomes of a concise review of existing food policy conceptualisations that are put forward in key writings. We show that although these conceptualisations have major value in outlining the broad contours of the food policy concept, ultimately they remain too imprecise. We then proceed by discussing a heuristic that 
helps to distinguish food policies from other (food-related) policies. Subsequently, we propose a set of policy dimensions that can be used to compare food policies along their main components. We end with a concise discussion of promising future avenues of research.

Importantly, although we believe strengthening comparative assessments of food policy initiatives is vital to the field, this is not to argue that all food policy scholars ought to adopt such an ontology or theoretical orientation. However, while we believe in the value of ontological and theoretical multiplicity, we consider the current lack of the type of research we propose a gap in the food policy literature.

\section{A review of existing food policy conceptualisations}

Table 1 provides an overview of how scholars have defined or conceptualised food policy in previous studies. Peer-reviewed articles were retrieved through a Scopus search of the 'food policy' concept. This body of literature was complemented with seminal books and reports, such as the Timmer et al. (1983) and Lang et al. (2009) volumes. The inclusion criterion was whether studies included an explicit conceptualisation, or defined the boundaries, of what constitutes food policy. Importantly, although we believe that these publications introduce the most frequently used interpretations of the concept, we do not claim to be exhaustive.

This overview confirms our observation in the previous section: there is no single, authoritative conceptualisation of what constitutes food policy. Many authors were found not to define or delineate the concept at all. Others have only put forward vague definitions, e.g., by arguing that food policy is about all actions or policy efforts that affect one or more food system dimension(s). There are also scholars who have put forward relatively precise definitions, which, however, differ considerably from each other. The overall picture that emerges is one that provides a reasonable sense of what food policy is or may be about, but at the same time is subject to considerable ambiguity. Comparing existing conceptualisations within the Policy Sciences literature, we distil three broad clusters of distinct food policy interpretations and levels of analysis: as policy outputs, institutional orders or discursive constructs.

Conceptualisations that approach food policy at the level of policy outputs are mainly interested in what governments (intend to) do, i.e. the goals governments set out and the means or actions through which these goals are pursued. Policy outputs refer to the programs, plans, regulations and other (semi-)legal products that are the direct result of decision-making processes (Knill and Tosun 2012). Following such an interpretation, food policy is understood as the policy or policies that governments, and possibly other public and private governance actors, adopt to govern one or more food system dimension(s). Such an interest can be extended to outcomes and impacts, i.e. the ways in which policies are implemented and the intended as well as unintended effects that result (Knill and Tosun 2012). Applying such an approach, scholars differ on whether they consider food policy as the potentially infinite range of policies that affect the functioning of the food system (e.g., Timmer et al. 1983; Lang et al. 2009) or adopt a more precise delineation. Such a delineation can either follow from a focus on a single food system activity or dimension (e.g., diet; see: Hawkes et al. 2015), or from focusing on the policies in a specific field or domain of policymaking, e.g., efforts to promote healthier diets within the field of public health. From a dependent variable problem perspective, not delineating the scope of policy outputs that is considered part of food policy is problematic, as it would leave any governmental action potentially relevant and as such make an empty shell out of the concept.

In addition, food policy may be used to refer to a set of policies that are not necessarily labelled as such by governments, or other governance actors, themselves. For example, Banik (2016) uses the label of food policy in relation to various Indian acts and programs that are usually labelled in different terms (e.g., 'food security') by the Indian government. This use of the food policy label is also common in many academic societies and communities, e.g., as illustrated by the journal Food Policy. In this sense food policy is essentially different from many other popular labels, such as 'environmental policy' or 'foreign policy' (cf. Lang et al. 2009), which generally overlap with the labels used by policymakers themselves.

A second cluster of food policy conceptualisations is concerned with polity or institutional orders, i.e. the institutional contexts within which the governance of food systems takes place. There is no agreed single definition of institutions (Streeck and Thelen 2005: 9). However, the various definitions share the assumption that institutions are sets of rules, norms and regularised practices with a rule-like quality that structure the behaviour of political, administrative and economic actors and which cannot be changed easily or instantaneously. Institutions are 'enduring features of political and social life (rules, norms and procedures) that structure behavior' (Scott 2008; Mahoney and Thelen 2009: 4; see also: Peters 2012). This approach is clearest in the conceptualisation by Feindt and Flynn (2009), who, taking an historical institutionalist approach, understand food policy as being constituted by 'multiple ... institutional layers that constitute 'multiple orders' (Lieberman 2002)'. According to Feindt and Flynn, the emergence of new concerns resulted in a process of institutional layering, through which food-related issues came to be embedded within different parts of the (British) political system. In principle, such an institutional order may also be less fragmented and can result in a more distinct food 
Table 1 Existing food policy conceptualisations

No. Author(s) (year) Conceptualisation or definition

$1 \quad$ Timmer et al. (1983)

iPES Food (2017)
'Food policy encompasses the collective efforts of governments to influence the decision-making environment of food producers, food consumers, and food marketing agents in order to further social objectives. These objectives nearly always included improved nutrition for inadequately nourished citizens and more rapid growth in domestic food production. Many countries also seek more equal income-earning opportunities and security against famines and other food shortages.' (p. 9)

No explicit definition of 'joined-up food policy', but: 'food policy offers a substantial challenge to governments as it reaches across a number of policy areas, demanding responses across these different policy sectors. ... In an era of multi-level governance such policy integration is not only required horizontally across policy sectors, but also vertically through different levels of governance.' (p. 557)

Discuss shift from 'old' to 'new' food policy. Identify a number of characteristics for both, but no explicit definition or conceptualisation.

'One everyday answer to the question 'what is food policy?' is that food policy is to food what economic policy is to economics, foreign policy is to foreign affairs and social policy is to the shaping of society. Such an answer makes the point that, although food policy may lack the profile of those other policy spheres, food has a policy framework nonetheless. Actions shape food outcomes. ... Food policy is thus about ... complex webs of interaction and, centrally, about how policies - deliberate and unintended affect food and its outcomes: who eats, what, when and how.' (p. 21-22)

'we arrive at a description of food policy as being constituted by multiple ideational and institutional layers that constitute 'multiple orders' (Lieberman 2002), the tensions between which are a constant internal source of policy change.'

Discusses desired Canadian food policy. No explicit definition or conceptualisation, although mentions a number of key challenges and key policy elements requiring change.

'Food policy means many different things to different people and we need to have some grasp of the technological and political complexity involved to understand its dynamics. ... At its most basic level, food policy is simple - it is policy concerning the production and distribution of food. But that conception of food policy is deceptively simple and as soon as we begin to examine the political and social dimensions then a number of vexing questions arise. ... The first point to consider is that food policy is about more than production, it also involves issues of food safety, distribution, allocation, and consumption. ... Food policy has increasingly come to be defined as security policy.' (p. 3-5)

'food policies are defined as actions that aim to improve the human diet. We focus on policies at the consumer-end of the food system, recognising that they have the potential to influence both supply and demand. We define effective food policies as those that successfully influence one of the key determinants of obesity: diet.' (p. 2410)

Discusses development of India's food policy over time; no explicit delineation.

Refer to 'food policy issues, such as the labelling of genetically modified organisms or new nutrition guidelines.' (p. 359) Argue that through social movement activism these are linked to long-standing social and political values related to environment, food safety, animal welfare, and public health, not solely economic interests.

'Whereas in the past, food policy was primarily used to indicate the whole range of policy efforts that affect food system outcomes, the notion has more and more come to be used to emphasise the need for integrative strategies that align these policy efforts into a concerted whole. Such concerted efforts would entail pursuing a shared vision of future food systems through coherent sectoral policy goals and a supportive and consistent mix of policy instruments (cf. Rayner and Howlett 2009).'

'An urban food policy is a concerted action on the part of city government to address food-related challenges. Urban food policies often emerge through significant involvement of civil society and other actors ... however, grassroots, citizen-led actions that are independent of governments do not constitute food policies per se.'

'Urban food policies run across a spectrum from integrated approaches to single-issue policies (Calori and Magarini 2015; Bricas 2017). Integrated urban food policies refer to policies seeking to address multiple food systems challenges, and typically require multiple government departments and policy areas to be bridged and novel governance bodies to be established. The process of developing integrated urban food policies often starts with an assessment of all the food-related challenges faced by the city, and the whole range of policy levers the city has at its disposal to deal with them (Bricas 2017).'

'However, most urban food policies consist of targeted actions with specific goals, such as addressing a specific public health or environmental concern (e.g. obesity, food waste). Such actions can pave the way for - and be incorporated into - integrated food policies at a later stage and may also have benefits in other policy areas.' (p. 9) 
policy sector, as is implicitly suggested by the conceptualisation by Lang et al. (2009).

A third cluster approaches food policy as a discursive construct, i.e. an idea or set of ideas about how food systems ought to be governed. This is clearest in the approach of Barling et al. (2002), who introduce the notion of 'joined-up food policy' as a desirable governance principle. Similarly, for many of the governments who have recently stated the ambition to strengthen food policy the concept has a strong integrative and normative connotation (Candel and Pereira 2017). These examples at the same time show that food policy as a discursive construct is closely related to policy outputs or institutional contexts. Food policy may also be interpreted as encompassing, or being constituted by, a broader range of ideas about food and related policies, as underlined by the focus of Feindt and Flynn (2009) on multiple ideational (in addition to institutional) layers.

The distinction between these three clusters shows that 'food policy' research encompasses different levels of analysis, all of which correspond with existing empirical phenomena. As an implication, it is vital to be clear about what one means when referring to the concept. Following on the recent emergence of actual food policies in many governance systems, in this paper we are primarily interested in the level of policy outputs. We believe that systematic assessments and comparisons of food policy outputs may over time allow for developing a strengthened knowledge base about the potential that different types and combinations of policy interventions have in achieving desired food system outcomes and impacts (cf. Knill and Tosun 2012: 292-293), such as reduced food insecurity, strengthened public health and/or enhanced environmental sustainability. Food policy as institutional orders and discursive devices seem relevant independent variables to explain variations of outputs across time and place, and may on their own be important study objects.

Having clarified our position vis-à-vis the existing food policy literature, this raises the question of how to delineate food policy as a study object. For example, if food policy analysts are interested in policy outputs, which outputs should one focus on and how?

\section{Specifying the dependent variable}

As a starting point for delineating food policy, Ingram's (2011: 425) simplified outline of the food system is useful. At an overall level, he distinguishes between four general food system activities: production, processing and packaging, distribution and retailing, and consumption. These activities produce a number of outcomes, which correspond with the four dimensions of food security that are commonly distinguished: food availability, access, utilisation, and the stability of these three over time. Though 'food security' will not always be policymakers' preferred framing, these dimensions are sufficiently broad also to encompass broader food-related issues, such as food safety and health (utilisation), social equality (access), and sustainability (stability). In addition to the four clusters of food systems activities, these outcomes are also affected by broader social and environmental conditions (other, more elaborate food system conceptualisations, distinguish many more categories of determinants, see, e.g.,: iPES Food 2015; Kennedy and Liljeblad 2016).

A specific challenge in defining food policy is that unlike many other policy fields, ${ }^{1}$ it does not have a single overall purpose or direction. Rather, it is a multi-dimensional policy that addresses various aspects of the food system. It can take many different shapes depending on the specific issues that are addressed, how they are prioritised, policy capacities, institutional conditions, political conditions, etc. Nor is food policy an established policy field in most polities; rather, it tends to reflect a desire to integrate food related policies into a coherent policy complex or strategy. What makes delineating food policy a challenge is that many policies are not designed with the explicit purpose of affecting food system activities. Nevertheless, they may have an impact on these activities and can thus be referred to as 'food policy' (see the discussion of the conceptualisations of Timmer et al. and Lang et al. in Section 2).

To overcome this challenge, Lundqvist's (1996: 16) distinction between functional, institutional and purpose-based approaches to delineate environmental policy can be readily transferred to the study of food policy. Lundqvist argues that in the functional approach, all policies that affect the natural environment will be considered environmental policy. Applying an institutional approach, only policies decided and implemented within particular parts of the political and administrative system (i.e. environmental committees in parliament, environmental ministries, environmental protection agencies etc.) are considered environmental policy. When defined by purpose, policies intended to improve the natural environment or prevent its deterioration are considered environmental policy. When applying Lundqvist's distinction to food policy, a functional approach would include too broad a range of policies and clearly stretch the concept too far. On the contrary, the institutional approach would include too little, as only policies decided and implemented by a few political and administrative organisations would count as food policies. When delineated by purpose, policies intentionally designed and, ideally, implemented to affect food system activities will fall under the heading of food policy. Adopting this approach would prevent scholars falling in the trap of not setting any boundaries. Of course, food policy scholars who do not aim for systematic comparisons may still choose for a functional or institution-based approach.

\footnotetext{
${ }^{1}$ Such as climate change policy (which has as its main objectives to mitigate or adapt to global warming).
} 
Relating these considerations back to Ingram's conceptualisation of the food system, we define food policy as a set of policy outputs adopted to address one or more food system activities with the explicit aim of affecting food system outcomes in a desired direction.

Policies purposefully adopted to influence food system activities can take different directions depending upon the specific food challenges that countries face, how these are politically prioritised and the political and institutional factors affecting policy formulation and implementation processes. Consequently, the way in which governments attempt to influence the four food system activities varies significantly across countries and over time. We therefore suggest leaving the question of 'what desired directions' as an open empirical question. To address this question and to compare food policies across contexts, the next step is to identify the dimensions that define the nature of policy.

\section{Conceptualising the four dimensions of food policy: a heuristic}

When defining social science concepts, the scholar should identify the core dimensions of the phenomenon and use these as the basis for the conceptualisation (Goertz 2006). We propose four core dimensions along which empirical manifestations of policy occur: (i) scope, (ii) degree of targeting, (iii) substantiality, and (iv) degree of integration. These four dimensions of policy have been extracted from conceptual discussions in the Policy Sciences (e.g. Howlett 2009, Jordan and Lenschow 2010). Goertz (2006) suggests that concepts are treated as continuums. Inspired by this suggestion, we consider the four dimensions continua: narrow-broad scope, specific-general targeting, high-low substantiality and loosely-highly integrated. By applying the four core dimensions to unpack food policy, food policy studies can remain in dialogue with and be situated within the broader Policy Sciences discipline. This discipline pursues an applied research agenda but at the same time remains firmly rooted in and contributes to the social sciences.

The first dimension is the scope of a food policy: which policy problems related to food does it address? This can vary from a narrow scope in which, for example, food production is the main concern to a wide scope in which the policy complex includes a broad range of policy dimensions that aim at affecting all four food system activities: food production, processing and packaging, distribution and retailing and consumption. Each of these activities can be more or less broadly defined. For instance, the production dimension can include concerns about farmers' income, the type of preferred production unit (e.g., the family farm) and a number of public good concerns such as the environmental sustainability of production, animal welfare, and preserving cultural landscapes.
Secondly, the degree of targeting may vary across the four food system activities. Targeting can be considered a multilayered specification of intentionality and involves the precision with which a policy's objectives are linked to the stated desired outcomes of a policy strategy (cf. Linder and Peters 1989). Howlett (2009) distinguishes between three levels of goals, ranging from 'general abstract policy aims' to 'specific policy targets'. At the intermediate level, we find 'operationalizable policy objectives'. The general abstract aims are defined as the 'most general macro-level statement $[\mathrm{s}]$ of government aims and ambitions in a specific policy area'. They state the government's intentions, often in the long term, using general language, for example a statement on the need to reduce the food system's climate emissions. While providing some overarching guidelines for the design of the policy, they are mostly meant for showing the public that a policy problem is being addressed. Operationalizable policy objectives refers to the 'specific meso-level areas that policies are expected to address in order to achieve policy aims'. These objectives clarify which aspects of a policy problem is to be addressed by the policy measures and perhaps how they are to be prioritised in terms of resource allocation or sequence. For instance, a food policy strategy may state or indicate how policy efforts relating to each of the four dimensions of food security are to be prioritised. Specific policy targets are defined as 'specific, on-the-ground micro requirements necessary to attain policy objectives'. They translate the policy aims and objectives into specific outcomes to be achieved, which can be accompanied by a specific timetable. The selection of these targets is thus pre-structured and -conditioned by the broader objectives (Howlett 2009). An example of a specific target would be the reduction of a country's agricultural sector's anthropogenic greenhouse gas emissions by $x$ percent to meet the 2-degree global target (cf. Wollenberg et al. 2016).

The degree of targeting can vary substantially across individual dimensions of policies designed to affect food system outcomes and even within the various aspects addressed under a dimension. For instance, agricultural policy that has been transformed into food policy without fundamental reorientation may be characterised by a high degree of targeting of farm related aspects falling under the production dimension. Sustainable production aspects may be more loosely targeted by formulation of targets in general terms and thus only vaguely committing government to pursue specific action.

The third dimension is substantiality. This refers to the extent to which policies contain the actual means to pursue the objectives and targets set out to be achieved (Dupuis and Biesbroek 2013). Substantiality can vary significantly across countries, over time and across each food system activity being addressed. In operational terms, the substance of policy is defined by the mixture of policy instruments applied. Policy instruments can be defined as 'the set of techniques by which governmental authorities wield their power in attempting to 
ensure support and effect or prevent social changes' (Verdung 1998: 21). Research on policy instruments has devoted considerable effort to developing policy instrument typologies, but an authoritative typology has not yet emerged (see Hood (2007) for a review of the policy instrument literature. See also Hood (1983), Verdung (1998), Howlett (2005), Lascoumes and Le Gales (2007), Howlett (2009) for different examples of instrument typologies). Here we apply Hood's classic distinction between governing resources based upon information (informative instruments), authority (regulatory instruments), treasure (economic instruments) and organisation (Hood 1983). This distinction between instruments based upon differences in their motivational rationales, i.e. information, rules, economic incentives and 'architectures' respectively, has proved quite robust since it underpins many instrument typologies (Hood 2007: 141).

The degree of substantiality can be established on the basis of an analysis of the policy instrument combination being applied and the specific calibration of the policy instruments (Table 2). Substantiality can be considered a scale running from low to high (see Daugbjerg and Sønderskov 2012). A low level of substantiality is characterised by the application of policy instruments that are non-binding and thus not constraining for the target group such as farmers, food manufacturers, retailers or consumers. A high level of substantiality is indicated by the use of more binding measures, a wider range of instruments being applied, and calibration of these instruments at a higher level. Table 2 provides an overview of what food policy instrument mixes might look like for both of these extremes.

Similarly to targeting, the degree of substantiality can vary significantly across the food system activities and within the individual components under each activity. For instance, production may be addressed by more substantive instruments than consumption, and within the production dimension, farm income may be more substantially addressed than sustainable production issues.

The fourth and final dimension entails the degree of policy integration of actual food policy manifestations. Policy integration refers to the extent to which a cross-cutting problem, here the overall functioning of or specific challenges within the food system, is addressed in a more or less holistic manner by a governance system's policy configuration (cf. Candel and Biesbroek 2016). Whereas various ways of operationalising policy integration exist (see also: Jordan and Lenschow 2010; Cejudo and Michel 2017; Tosun and Lang 2017), all of these share an interest in the coherence of policy goals and the consistency of instruments. As such, this dimension relates directly back to the previous three dimensions (coherence to the scope and targeting, consistency to substantiality). Coherence involves the extent to which food policies' goals are aligned vis-à-vis one or more overarching objectives (e.g., reducing malnutrition or environmental footprints). Consistency is about whether there is a mix of complementary instruments that help pursuing goals and objectives (Howlett and Rayner 2007). Both coherence and consistency can be assessed within a policy (e.g. are targets aligned with each other and with broader objectives), but also between food policies, partly depending on how a food policy complex is organised within a polity. Regarding this last point, whereas some polities may possess a single, overarching food strategy, others may have integrated food-related concerns across a range of (intentional) policies and seek to organise connectivity between these (a combination of these is also possible) (Candel and Pereira 2017).

Unfortunately, no agreed-upon methods to assess objectively coherence and consistency have been developed so far. Instead, scholars have proposed to use expert groups

Table 2 Low and high substantiality

\begin{tabular}{|c|c|c|}
\hline Instrument types & Calibration for low substantiality & Calibration for high substantiality \\
\hline Informative & $\begin{array}{l}\text { Relatively intensive use of information and education. } \\
\text { E.g., mass information campaigns on healthy consumption }\end{array}$ & $\begin{array}{l}\text { Intensively used; complementary to other instrument types. } \\
\text { E.g., compulsory 'traffic light' labelling on food products }\end{array}$ \\
\hline Economic & $\begin{array}{l}\text { Use of taxes and subsidies with low monetary level which } \\
\text { mostly serve symbolic purposes. } \\
\text { E.g., a fat tax set at a relatively low level, or farm subsidies } \\
\text { for maintaining organic farming }\end{array}$ & $\begin{array}{l}\text { Significant use of taxes or subsidies providing strong } \\
\text { incentives for behavioural change. } \\
\text { E.g., sugar and fat taxes set at a high level and targeted at } \\
\text { promoting healthier consumption, or subsidies for } \\
\text { converting to organic farming }\end{array}$ \\
\hline Regulation & $\begin{array}{l}\text { Modest: some minimum standards for production, } \\
\text { processing or marketing. Preference for self-regulation. } \\
\text { E.g., limitations on advertising of alcoholic beverages in } \\
\text { prime time television shows, or encouraging industry to } \\
\text { self-regulate salt contents of food products }\end{array}$ & $\begin{array}{l}\text { Binding instruments such as prohibitions. Self-regulation } \\
\text { under shadow of hierarchy. } \\
\text { E.g., prohibiting the use of certain food additives through } \\
\text { legislation, or a ban on selling fast-food in the proximity } \\
\text { of schools. }\end{array}$ \\
\hline Organisation & $\begin{array}{l}\text { Limited investment in organisation building. Often limited } \\
\text { to support informative instruments. } \\
\text { E.g., establishing a desk to assist with subsidy applications }\end{array}$ & $\begin{array}{l}\text { Variety of organisations with food-related purposes being } \\
\text { established or redesigned. } \\
\text { E.g., establishing a nutrition agency with research } \\
\text { institutions and information campaign units }\end{array}$ \\
\hline
\end{tabular}


(Nilsson et al. 2012) or a proximity-to-target measure (Candel and Biesbroek 2016), in which the existing constellation of goals and instruments is compared to a pre-developed ideal type. In addition, Candel and Biesbroek (2018) developed various proxy-indicators in their assessment of policy integration in the European Union governance of global food security.

\section{Conclusion}

This paper started from the observation that the development of a comparative food policy research agenda has been hampered by the dependent variable problem of how to delineate food policy. Through a concise literature review we showed that the existing literature has interpreted food policy in three different ways: as policy outputs, institutional orders, or a discursive construct. We proposed to focus on outputs when defining food policy. The question of what policy outputs should be considered food policy can be overcome by using a purpose-based selection criterion, i.e. policy efforts are considered food policy when they are intentionally designed to steer one or more food system activities (production, processing and packaging, distribution and retailing, and consumption) towards desired directions. We then suggested a heuristic encompassing four dimensions along which food policies may differ: policy scope, targeting of policy efforts, type of policy instruments applied and integration of the various components of the policy complex. These four dimensions can be applied to characterise individual food policies and compare across cases.

The heuristic is purely descriptive and designed to map and compare food policies across countries and over time. It does not suggest hypotheses on the conditions enabling the formation of different food policy designs. Nor does it suggest what the impacts of the four policy dimensions are. This does not mean, however, that the heuristic cannot be used in explanatory endeavours. It can be applied to conceptualise and define categories on the dependent variable of a single-case or comparative study. After having categorised a country's or a selection of countries' food policies on the basis of the heuristic, the scholar would search for variables explaining similarities or differences across countries. While the heuristic would be useful in categorising food policies, the explanatory exercise is external to it.

Likewise, the typology could be useful in studies intending to evaluate the effects of different food policies. In undertaking food policy evaluations, the heuristic would enable the mapping of different combinations of policy measures and objectives and thus provide a starting point for an evaluation of effects; in other words, categorising the independent variable in evaluation studies (cf. Knill and Tosun 2012: 292293). Taking a step further, the heuristic could be used as a basis for generating hypotheses about the possible impacts of different types of food policies (see Daugbjerg and Sønderskov 2012: for an example of such a use of a policy typology of organic food policies based on a similar two-bytwo table format). This would inject some explanatory power into the heuristic and can be considered the next step in further developing it.

Apart from its scientific relevance, moving towards such evaluation of food strategies could also feed into current political debates. The role that governments (ought to) take in governing food systems as well as the instruments by which they do so have proven to be at least as controversial as defining the broader directions in which food systems should develop. Political decision-makers have been criticised for being paternalistic or creating too heavy regulatory burdens when using instruments with substantial impact, while being accused of inertia or symbolic policymaking when adopting less far-reaching tools. Although such contestations are associated with governing all complex problems, studying how food policy works in practice will at least provide a stronger knowledge basis for such debates.

More generally, the development of a comparative research agenda and systematic tracking of food policy efforts over time will strengthen possibilities to hold governments accountable, as it would create benchmarks and provide insights into whether governments proceed beyond symbolic commitments. Additionally, it would allow policymakers themselves to gain better insights into (best) practices elsewhere, possibly resulting in the diffusion of effective interventions.

\section{Compliance with ethical standards}

Conflict of interest The authors declared that they have no conflict of interest.

Open Access This article is distributed under the terms of the Creative Commons Attribution 4.0 International License (http:// creativecommons.org/licenses/by/4.0/), which permits unrestricted use, distribution, and reproduction in any medium, provided you give appropriate credit to the original author(s) and the source, provide a link to the Creative Commons license, and indicate if changes were made.

\section{References}

Banik, D. (2016). The hungry nation: Food policy and food politics in India. Food Ethics, 1(1), 29-45.

Barling, D. (Ed.). (2016). Advances in food security and sustainability. Cambridge/San Diego/Oxford/London: Academic.

Barling, D., Lang, T., \& Caraher, M. (2002). Joined-up food policy? The trials of governance, public policy and the food system. Social Policy \& Administration, 36(6), 556-574.

Berrang-Ford, L., Ford, J. D., \& Paterson, J. (2011). Are we adapting to climate change? Global Environmental Change, 21(1), 25-33. 
Bricas, N. (2017). Les enjeux de l'urbanisation pour la durabilité des systèmes alimentaires. In C. Brand, N. Bricas, D. Conare, B. Daviron, J. Debru, L. Michel, et al. (Eds.), Construire des politiques alimentaires urbaines: Concepts et demarches (pp. 19-38). Versailles: Editions Quae.

Calori, A., \& Magarini, A. (2015). Food and the cities: Food policies for sustainable cities. Milan: Edizioni Ambiente.

Candel, J. J. L. (2018). Diagnosing integrated food security strategies. NJAS - Wageningen Journal of Life Sciences, 84, 103-113.

Candel, J. J. L. (2019). What's on the menu? A global assessment of MUFPP signatory cities' food strategies. Agroecology and Sustainable Food Systems. https://doi.org/10.1080/21683565.2019. 1648357.

Candel, J. J. L., \& Biesbroek, G. R. (2016). Toward a processual understanding of policy integration. Policy Sciences, 49(3), 211-231.

Candel, J. J. L., \& Biesbroek, R. (2018). Policy integration in the EU governance of global food security. Food Security, 10(1), 195-209.

Candel, J. J. L., \& Pereira, L. (2017). Towards integrated food policy: Main challenges and steps ahead. Environmental Science \& Policy, 73, 89-92.

Cejudo, G. M., \& Michel, C. L. (2017). Addressing fragmented government action: Coordination, coherence, and integration. Policy Sciences, 50(4), 745-767.

Crush, J. (2013). Linking food security, migration and development. International Migration, 51(5), 61-75.

Daugbjerg, C., \& Sønderskov, K. M. (2012). Environmental policy performance revisited: Designing effective policies for Green markets. Political Studies, 60(2), 399-418.

De Cunto, A., Tegoni, C., Sonnino, R., Michel, C., \& Lajili-Djalaï, F. (2017). Food in cities: Study on innovation for a sustainable and health production, delivery, and consumption of food in cities. Brussels: European Commission.

de Schutter, O. (2017). A food policy for Europe. Green European Journal.

Dupuis, J., \& Biesbroek, R. (2013). Comparing apples and oranges: The dependent variable problem in comparing and evaluating climate change adaptation policies. Global Environmental Change, 23(6), 1476-1487.

Ericksen, P. J., Ingram, J. S. I., \& Liverman, D. M. (2009). Food security and global environmental change: Emerging challenges. Environmental Science \& Policy, 12(4), 373-377.

Feindt, P. H., \& Flynn, A. (2009). Policy stretching and institutional layering: British food policy between security, safety, quality, health and climate change. British Politics, 4(3), 386-414.

Fresco, L. O., \& Poppe, K. J. (2016). Towards a common agricultural and food policy. Wageningen: Wageningen University.

Godfray, H. C. J., Crute, I. R., Haddad, L., Lawrence, D., Muir, J. F., Nisbett, N., et al. (2010). The future of the global food system. Philosophical Transactions of the Royal Society B: Biological Sciences, 365(1554), 2769-2777.

Goertz, G. (2006). Structuring and theorizing concepts. Princeton: Princeton University Press.

Green-Pedersen, C. (2004). The dependent variable problem within the study of welfare state retrenchment: Defining the problem and looking for solutions. Journal of Comoparative Policy Analysis: Research and Practice, 6(1), 3-14.

Hawkes, C., Smith, T. G., Jewell, J., Wardle, J., Hammond, R. A., Friel, S., et al. (2015). Smart food policies for obesity prevention. The Lancet, 385(9985), 2410-2421.

Holt-Giménez, E., \& Patel, R. (2012). Food rebellions: Crisis and the hunger for justice. Oakland: Food First Books.

Hood, C. (1983). The tools of Government. Basingstoke: Macmillan.

Hood, C. (2007). Intellectual obsolescence and intellectual makeovers: Reflections on the tools of Government after two decades. Governance, 20(1), 127-144.
Howlett, M. (2005). What is a policy instrument? In P. Eliadis, M. Hill, \& M. Howlett (Eds.), Designing Government (pp. 31-50). Montreal: McGill/Queens University Press.

Howlett, M. (2009). Governance modes, policy regimes and operational plans: A multi-level nested model of policy instrument choice and policy design. Policy Sciences, 42(1), 73-89.

Howlett, M., \& Cashore, B. (2009). The dependent variable problem in the study of policy change: Understanding policy change as a methodological problem. Journal of Comparative Policy Analysis: Research and Practice, 11(1), 33-46.

Howlett, M., \& Rayner, J. (2007). Design principles for policy mixes: Cohesion and coherence in 'new governance arrangements'. Policy and Society, 26(4), 1-18.

IFPRI. (2016). Global nutrition report 2016: From promise to impact: Ending malnutrition by 2030. Washington, DC: International Food Policy Research Institute.

Ingram, J. (2011). A food systems approach to researching food security and its interactions with global environmental change. Food Security, 3(4), 417-431.

Ingram, J., Ericksen, P., \& Liverman, D. (Eds.). (2012). Food security and global environmental change. Oxon: Routledge.

iPES Food (2015). The new science of sustainable food systems: Overcoming barriers to food systems reform. International Panel of Experts on Sustainable Food Systems.

iPES Food (2017). What makes urban food policy happen? Insights from five case studies. International Panel of Experts on Sustainable Food Systems.

Jordan, A., \& Lenschow, A. (2010). Policy paper environmental policy integration: A state of the art review. Environmental Policy and Governance, 20(3), 147-158.

Kennedy, A., \& Liljeblad, J. (Eds.). (2016). Food systems governance: Challenges for justice. Equality and Human Rights: Earthscan.

Knill, C., \& Tosun, J. (2012). Public policy: A new introduction. Basingstoke: Palgrave Macmillan.

Lang, T., Barling, D., \& Caraher, M. (2009). Food policy: Integrating health, environment \& society. Oxford: Oxford University Press.

Lascoumes, P., \& Le Gales, P. (2007). Introduction: Understanding public policy through its instruments-From the nature of instruments to the sociology of public policy instrumentation. Governance, 20(1), $1-21$.

Lentz, E. C., \& Barrett, C. (2013). The economics and nutritional impacts of food assistance policies and programs. Food Policy, 42, 151-163.

Lieberman, R. C. (2002). Ideas, institutions, and political order: Explaining political change. American Political Science Review, 96(4), 697-712.

Linder, S. H., \& Peters, B. G. (1989). Instruments of government: Perceptions and contexts. Journal of Public Policy, 9(1), 35-58.

Lundqvist, L. J. (1996). Environmental politics in the Nordic countries: Policy, organisation, and capacity. In P. M. Christiansen (Ed.), Governing the environment: Politics, policy, and organization in the Nordic countries (Vol. 5, pp. 13-27). Copenhagen: Nordic Council of Ministers.

MacRae, R. (2011). A joined-up food policy for Canada. Journal of Hunger \& Environmental Nutrition, 6, 424-457.

Mahoney, J., \& Thelen, K. (2009). Explaining institutional change: Ambiguity, agency, and power. New York: Cambridge University Press.

Marcondes, G., \& De Bruyn, T. (2015). Brazil's south-south cooperation in food security: Capacity building approaches of the Centre of Excellence against hunger. Food Security, 7(6), $1153-1164$.

Marsden, T. (2010). Food 2030: Towards a redefinition of food? A commentary on the new United Kingdom Government food strategy. The Political Quarterly, 81(3), 443-446. 
Marsden, T. (2015). Why not a common food and nutrition policy for Europe? http://www.transmango.eu/userfiles/food\%20policy\% 20opinion\%20terry\%20marsden.pdf. .

Marsden, T., \& Morley, A. (2014). Sustainable food systems: Building a new paradigm. Oxon: Routledge.

Maxwell, S., \& Slater, R. (2003). Food policy old and new. Development Policy Review, 21(5-6), 531-553.

Nilsson, M., Zamparutti, T., Petersen, J. E., Nykvist, B., Rudberg, P., \& McGuinn, J. (2012). Understanding policy coherence: Analytical framework and examples of sector-environment policy interactions in the EU. Environmental Policy and Governance, 22(6), 395-423.

Parsons, K. (2018). Constructing a national food policy: Integration challenges in Australia and the UK. London: University of London.

Peters, B. G. (2012). Institutional theory in political science: The new institutionalism (3rd ed.). New York: Continuum International Publishing Group.

Peters, B. G., \& Pierre, J. (2014). Food policy as a wicked problem: Contending with multiple demands and actors. World Food Policy, 1(1), 1-9.

Rahn, W. M., Gollust, S. E., \& Tang, X. (2017). Framing food policy: The case of raw Milk. Policy Studies Journal, 45(2), 359-383.

Rosin, C., Stock, P., \& Campbell, H. (Eds.). (2012). Food systems failure: The global food crisis and the future of agriculture. Abingdon: Earthscan.

Scott, W. R. (2008). Institutions and organizations: Ideas and interests (3rd ed.). Thousand Oaks, CA: Sage.

Streeck, W., \& Thelen, K. (2005). Beyond continuity: Institutional change in advanced political economies. Oxford: Oxford University Press.

Termeer, C. J. A. M., Drimie, S., Ingram, J., Pereira, L., \& Whittingham, M. J. (2018). A diagnostic framework for food system governance arrangements: The case of South Africa. NJAS - Wageningen Journal of Life Sciences, 84, 85-93.

Timmer, C. P., Falcon, W. P., \& Pearson, S. R. (1983). Food policy analysis. Baltimore: Johns Hopkins University Press for the World Bank.

Tosun, J., \& Lang, A. (2017). Policy integration: Mapping the different concepts. Policy Studies, 38(6), 553-570.

Van der Ploeg, J. D. (2008). The new peasantries: Struggles for autonomy and sustainability in an era of empire and globalization. London/ Sterling, VA: Earthscan.

Verdung, E. (1998). Policy instruments: Typologies and theories. In R. Bemalmans-Videc, C. Rist, \& E. Vedung (Eds.), Carrots, sticks and sermons: Policy instruments and their evaluation (pp. 21-58). New Brunswick: Transaction Books.

Vermeulen, S. J., Campbell, B. M., \& Ingram, J. S. I. (2012). Climate change and food systems. Annual Review of Environment and Resources, 37(1), 195-222.

WHO. (2015). WHO estimates of the global burden of foodborne diseases: Foodborne disease burden epidemiology reference group 2007-2015. Geneva: World Health Organization.

WHO. (2016). WHO urges global action to curtal consumption and health impacts of sugary drinks. Geneva: World Health Organization Accessed July 22, 2019, from https://www.who.int/ news-room/detail/11-10-2016-who-urges-global-action-to-curtailconsumption-and-health-impacts-of-sugary-drinks.

Wollenberg, E., Richards, M., Smith, P., Havlík, P., Obersteiner, M., Tubiello, F. N., Herold, M., Gerber, P., Carter, S., Reisinger, A., van Vuuren, D., Dickie, A., Neufeldt, H., Sander, B. O., Wassmann, R., Sommer, R., Amonette, J. E., Falcucci, A., Herrero, M., Opio, C., Roman-Cuesta, R. M., Stehfest, E., Westhoek, H., Ortiz-Monasterio, I., Sapkota, T., Rufino, M. C., Thornton, P. K., Verchot, L., West, P. C., Soussana, J. F., Baedeker, T., Sadler, M., Vermeulen, S., \& Campbell, B. M. (2016). Reducing emissions from agriculture to meet the $2{ }^{\circ} \mathrm{C}$ target. Global Change Biology, 22(12), 3859-3864.

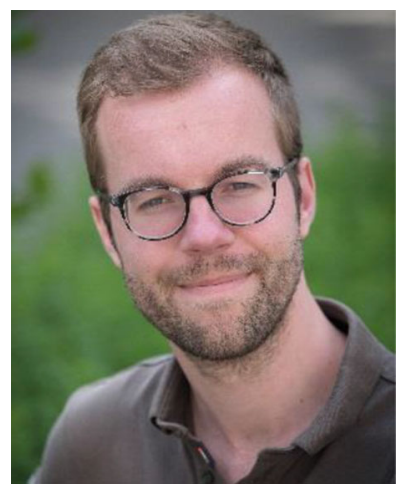

Dr Jeroen Candel is Assistant Professor at the Public Administration and Policy group, Wageningen University \& Research, the Netherlands. His research interests include food and agricultural policy, policy integration, wicked problems, and EU politics. $\mathrm{He}$ authored various papers on European food security governance, which have been published in both public policy and food (policy) journals. His most recent research focuses on governments' attempts to move towards better integrated food policy.

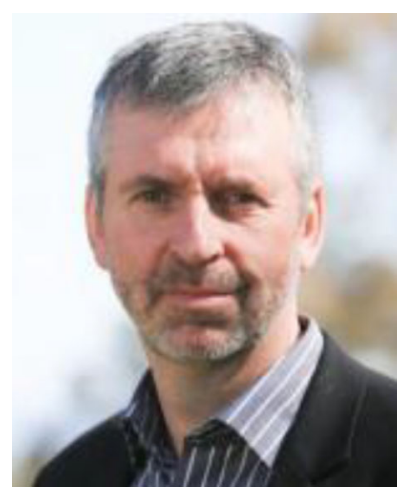

Carsten Daugbjerg is a political scientist and Professor in the Department of Food and Resource Economics, University of Copenhagen and an Honorary Professor in the Crawford School of Public Policy, The Australian National University. His research area is comparative and global public policy with a particular empirical interest in the role of interest groups in public policy, agricultural policy reform, farm trade negotiations in the WTO, private food standards and the WTO agreements, agri-environmental regulation, organic food policy and biofuels policy. His current research focusses on global food security policy and governance and private food standards. 